\title{
On the Reaction between Substituted Malonic Esters and Methylene Bromide. I
}

\author{
L E N N A R T E B E R S O N
}

Department of Organic Chemistry, Chemical Institute, University of Lund, Sweden

\begin{abstract}
Diethyl methyl-, ethyl-, $n$-propyl-, isopropyl-, $n$-butyl-, isobutyl-, $n$-amyl-, benzyl-, and acetaminomalonates in the form of their sodium compounds react with methylene bromide in ethanolic solution to form 1,3-disubstituted 1,1,3-tricarbethoxypropanes with the elimination of one carbethoxy group as diethyl carbonate, whereas diethyl phenyland carbethoxymalonate give 1,3-disubstituted 1,3-dicarbethoxypropanes with the elimination of two carbethoxy groups. Diethyl neopentylmalonate yields a-neopentylacrylate, and diethyl tert.-butylmalonate and ethyl phenylacetate give no reaction. A reaction scheme is proposed. The preparation of the corresponding glutaric acids from the esters above is described.
\end{abstract}

The present investigation deals with the reaction between substituted 1 malonic esters and methylene bromide and its use for the preparation of $\alpha \alpha^{\prime}$-disubstituted glutaric acids. The author has previously found ${ }^{1}$ that when the sodium compound of diethyl trimethylsilylmethylmalonate $(I, \quad R=$ $\left.\left(\mathrm{CH}_{3}\right)_{3} \mathrm{SiCH}_{2}\right)$ was allowed to react with methylene bromide in ethanolic solution a triethyl ester was obtained according to formula (1):

2 R.CH $(\mathrm{COOEt})_{2}+\mathrm{CH}_{2} \mathrm{Br}_{2}+2 \mathrm{OEt}^{-} \longrightarrow$ I

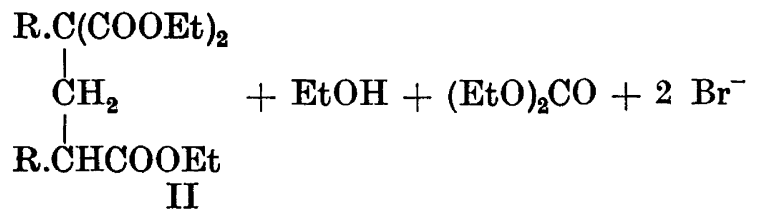

i.e., one carbethoxy group was eliminated. Attempts to prepare the tetraethyl ester by carrying out the synthesis in an inert solvent (toluene or xylene) at a higher temperature resulted in the formation of diethyl bromomethyl-tri- 
methylsilylmethylmalonate (III, $\left.\mathrm{R}=\left(\mathrm{CH}_{3}\right)_{3} \mathrm{SiCH}_{2}\right)$ which did not react further with a second molecule of I:

$\mathrm{R} . \mathrm{C}(\mathrm{Na})(\mathrm{COOEt})_{2}+\mathrm{CH}_{2} \mathrm{Br}_{2} \underset{140^{\circ}}{\stackrel{\text { xylene }}{\longrightarrow}} \mathrm{R} . \mathrm{C}\left(\mathrm{CH}_{2} \mathrm{Br}\right)(\mathrm{COOEt})_{2}+\mathrm{NaBr}$

III

An examination of the literature on similar reactions yielded incomplete and with the above result incompatible information, and therefore a more detailed study of the reaction was undertaken. Guthzeit and Dressel ${ }^{2,3}$ stated that diethyl malonate and methylene iodide gave 1,1,3,3,-tetracarbethoxypropane in about $80 \%$ yield, diethyl ethylmalonate and methylene iodide a mixture boiling over a large interval ${ }^{3}$, and diethyl benzylmalonate and methylene iodide 1,3-dibenzyl-1,1,3,3-tetracarbethoxypropane ${ }^{3}$. Diethyl methylmalonate and methylene iodide gave 1,3-dimethyl-1,1,3,3-tetracarbethoxypropane according to Bischoff ${ }^{4}$ and von Auwers ${ }^{5}$. Diethyl acetaminomalonate did not react with methylene iodide ${ }^{6}$. Souther ${ }^{7}$ found that diethyl phenylmalonate and methylene iodide reacted according to formula (3):

$$
2 \mathrm{R}^{\prime} \cdot \mathrm{CH}(\mathrm{COOEt})_{2}+\mathrm{CH}_{2} \mathrm{I}_{2}+2 \mathrm{OEt}^{-} \longrightarrow
$$

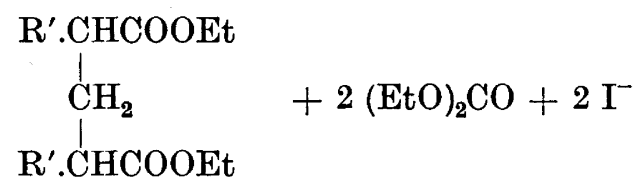

IV

$$
\left(\mathrm{R}^{\prime}=\mathrm{C}_{6} \mathrm{H}_{5}\right. \text { or COOEt) }
$$

i.e., two carbethoxy groups were eliminated. However, of the above statements only the first- and last-mentioned were wholly established while the others were not demonstrated satisfactorily.

The following substituted malonic esters were investigated with respect to their reaction with methylene bromide in ethanolic solution: diethyl methyl-, ethyl-, $n$-propyl-, isopropyl-, $n$-butyl-, isobutyl-, tert.-butyl-, $n$-amyl-, neopentyl-, phenyl-, benzyl-, carbethoxy-, and acetaminomalonate. Ethyl phenylacetate was also investigated.

Diethyl methyl-, ethyl-, $n$-propyl-, isopropyl-, $n$-butyl-, isobutyl-, $n$-amyl-, benzyl-, and acetaminomalonate all reacted according to formula (1) to yield the triesters II. To establish that the inconsistency with the statements from the literature was not due to the nature of the halogenide, methylene iodide was also used in the reaction with diethyl methyl-, ethyl-, and benzylmalonate. However the same result was obtained. Diethyl tert.-butylmalonate and ethyl phenylacetate did not give any reaction at all, whereas diethyl neopentylmalonate reacted according to formula (4):

$$
\begin{aligned}
& \left(\mathrm{CH}_{3}\right)_{3} \mathrm{CCH}_{2} \mathrm{CH}(\mathrm{COOEt})_{2}+\mathrm{CH}_{2} \mathrm{Br}_{2}+2 \mathrm{OEt}^{-} \longrightarrow \\
& \left(\mathrm{CH}_{3}\right)_{3} \mathrm{CCH}_{2} \mathrm{C}=\mathrm{CH}_{2}+\mathrm{EtOH}+(\mathrm{EtO})_{2} \mathrm{CO}+2 \mathrm{Br}^{-} \\
& \text {COOEt }
\end{aligned}
$$


The ethyl $\alpha$-neopentylacrylate was identified by conversion to the corresponding acid, which was known from the work of Hadley et al. ${ }^{8}$ Diethyl phenylmalonate and tricarbethoxymethane reacted according to formula (3).

A few bromomethyl-alkylmalonates (III, $\mathrm{R}=\mathrm{CH}_{3}, \mathrm{C}_{2} \mathrm{H}_{5}, n-\mathrm{C}_{5} \mathrm{H}_{11}$, and neo- $\mathrm{C}_{5} \mathrm{H}_{11}$ ) were prepared in toluene solution with excess of methylene bromide. These compounds were thermally stable up to $300^{\circ} \mathrm{C}$. III, $\mathrm{R}=\mathrm{CH}_{3}$, reacted with the sodium compound of diethyl methylmalonate to give $\mathrm{II}, \mathrm{R}=\mathrm{CH}_{3}$.

The triethyl esters with $\mathrm{R}=$ methyl, ethyl, and isopropyl were hydrolyzed and decarboxylated directly by boiling with $70-80 \%$ sulphuric acid, while that with $\mathrm{R}=$ acetamino was converted into $\alpha \alpha^{\prime}$-diaminoglutaric acid according to the method of Hellman, Lingens, and Folz ${ }^{6}$. The other compounds were hydrolyzed by boiling with $10 \%$ ethanolic potassium hydroxide (the acid hydrolysis was not used on account of the insolubility of the acids formed in this medium) and the tricarboxylic acids could then easily be decarboxylated by heating to $160-170^{\circ}$. The glutaric acids could be separated into highand low-melting forms by fractionated crystallization from suitable solvents.

\section{DISCUSSION}

The first step in the reaction between a methylene halogenide and a substituted malonic ester in ethanol must be the formation of a bromomethylmalonic ester (III) according to formula (2). The next step is the reaction of an ethoxide ion with III to form the intermediate anion $\mathrm{V}$ which then decomposes into an $\alpha$-substituted acrylic ester (VI) with the<smiles>[X]CC([R2])C(=O)OCC#CC=CC(=O)OCC</smiles>

elimination of one molecule of diethyl carbonate and one halide ion:

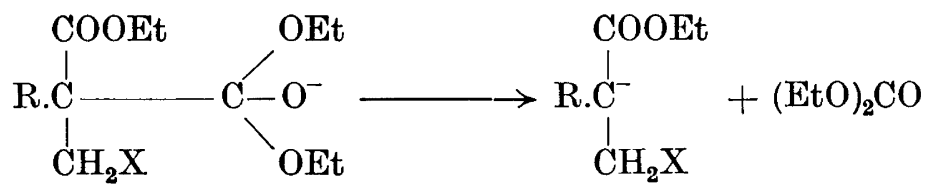

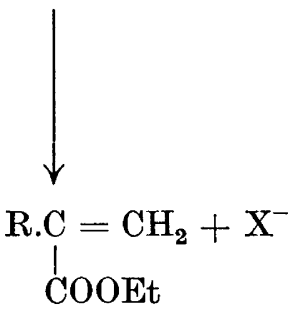


The last stage consists of a Michael addition of VI to a second molecule of the malonic ester (7):

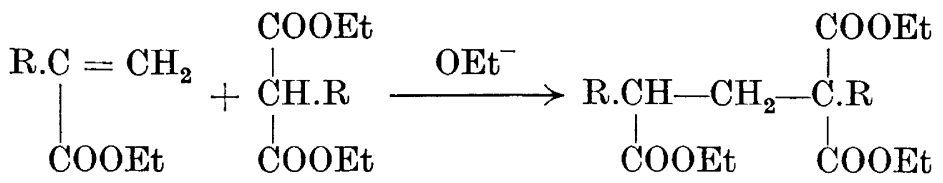

There is much evidence which favours the above reaction sequence. The formation of the bromomethylmalonic ester III is usually difficult to accomplish in ethanolic solution even with a large excess of methylene halogenide as it immediately reacts further with ethoxide ion. However, when $\mathbf{R}$ is a bulky group as trimethylsilylmethyl, the bromo compound can be isolated in good yield ${ }^{1}$. This is not possible with malonic esters containing small $\mathrm{R}$ groups (e.g. methyl or ethyl). A compound of the type III possesses a neopentyl structure and thus is very unlikely to react according to an $S_{N} 2$-mechanism with an R. C(COOEt) ${ }_{2}$-ion. Instead the bromomethyl group, being an electronegative substituent, promotes the elimination of a carbethoxy group by ethoxide ion. This cleavage reaction has been found to be enhanced by other electronegative groups such as the phenyl ${ }^{9-11}$, nitro ${ }^{12}$, vinyl ${ }^{13}, 2$,4-dinitrophenyl ${ }^{14}, 2$ - or 3 -indenyl ${ }^{15}$, and dichloromethyl group ${ }^{16}$. The behaviour of dichloromethyl-alkylmalonic esters towards ethoxide ion has been studied by Bowman and Rexford ${ }^{16}$ and they proposed the following reaction mechanism for the reaction:

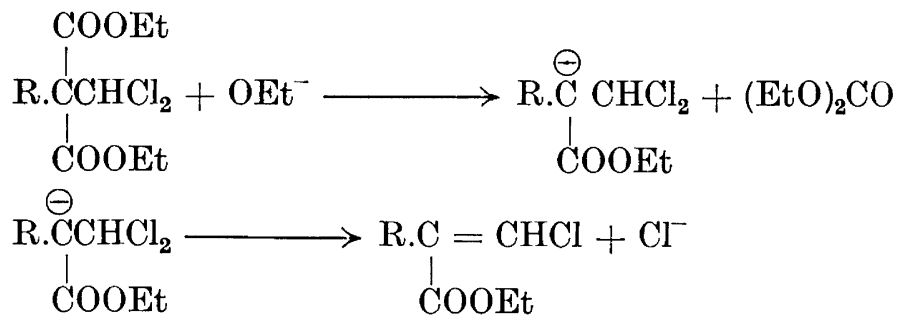

Reactions (8) and (9) are analogous to (5) and (6).

The elimination of two carbethoxy groups when $\mathrm{R}$ is phenyl or carbethoxy, i.e., an electronegative substituent, is readily explained by the reactions (10), (11), and (12):

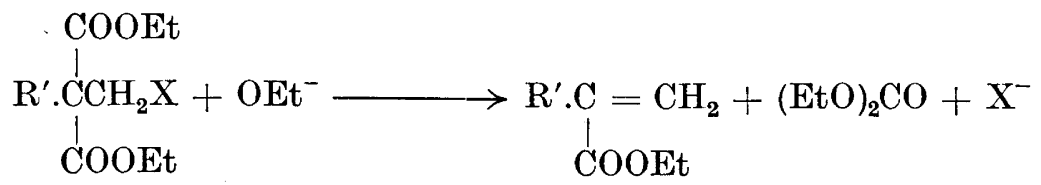

$$
\mathrm{R}^{\prime} \cdot \mathrm{CH}(\mathrm{COOEt})_{2}+\mathrm{OEt}^{-} \longrightarrow \mathrm{R}^{\prime} \cdot \overline{\mathrm{CHCOOEt}}+(\mathrm{EtO})_{\mathbf{2}} \mathrm{CO}
$$

Acta Chem. Scand. 12 (1958) No. 2 


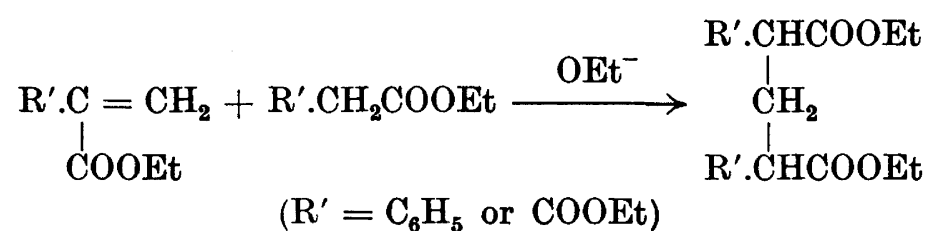

The alternative route whereby a malonic ester of this type first reacts according to formula (11) and then according to (13)

$2 \mathrm{R}^{\prime} \mathrm{CH}_{2} \mathrm{COOEt}+\mathrm{CH}_{2} \mathrm{X}_{2}+2 \mathrm{OEt}^{-} \longrightarrow$

$\mathrm{R}^{\prime}$.CHCOOEt

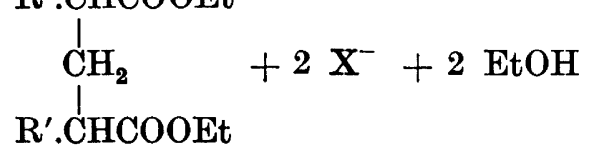

$$
\left(\mathrm{R}^{\prime}=\mathrm{C}_{6} \mathrm{H}_{5}\right. \text { or COOEt) }
$$

can be ruled out in the case of $R^{\prime}=$ phenyl, as ethyl phenylacetate fails to react with methylene bromide. This is not so in the case of $R^{\prime}=$ carbethoxy, however, where both reaction paths are possible.

The isolation of the intermediate $\alpha$-substituted acrylic ester has been accomplished for $\mathrm{R}=$ neopentyl. It is possible that this reaction may be used as a good preparation method for such compounds after certain modifications, but no experiments in this direction have yet been undertaken.

The last step (7) has been demonstrated for $\mathrm{R}=$ methyl by von Auwers and Köbner ${ }^{17}$, Hoch and Karrer ${ }^{18}$, and Ruhl ${ }^{19}$.

As a general preparation method for $\alpha \alpha^{\prime}$-disubstituted glutaric acids the reaction has several advantages over the existing ones. The starting materials are easily available and the reaction products are easy to isolate and purify. The most serious limitation is the failure of malonic esters containing bulky $\mathrm{R}$ groups (such as tert.-butyl and neopentyl) to react. The unreactivity of diethyl tert.-butylmalonate may in part be due to the considerably reduced acidity of this compound in ethanolic solution as compared with $n$-alkylmalonic esters.

\section{EXPERIMENTAL}

All reagents used were carefully dried and fractionated in a glass-helix packed column of about ten theoretical plates. In the malonic ester syntheses precautions were taken to exclude moisture from the reaction vessels. Determinations of the melting points were made with a Kofler micro hot stage. The analyses were carried out at the Department of Analytical Chemistry, Chemical Institute, Lund.

1,3-Dimethyl-1,1,3-tricarbethoxypropane $\left(I I, R=\mathrm{CH}_{3}\right)$. To a solution of $4.6 \mathrm{~g}$ $(0.2 \mathrm{~mole})$ of sodium in $80 \mathrm{ml}$ of absolute ethanol $34.8 \mathrm{~g}(0.2 \mathrm{~mole})$ of diethyl methylmalonate was added, followed by $17.4 \mathrm{~g}(0.1 \mathrm{~mole})$ of methylene bromide. The reaction mixture was boiled for $20 \mathrm{~h}$ after which time it was almost neutral. It was neutralized with a few drops of glacial acetic acid, the ethanol was distilled off through a short column, and water added to dissolve the sodium bromide. The organic layer was taken up in 
ether, the ether solution washed with water, and finally dried with anhydrous magnesium sulphate. After distilling off the ether the residue was distilled in vacuo. This method yielded $7.5 \mathrm{~g}(64 \%)$ of diethyl carbonate, b. p. $65-70^{\circ} / 60 \mathrm{~mm}$, and $24.0 \mathrm{~g}(83 \%)$ of 1,3 . dimethyl-1,1,3-tricarbethoxypropane, b. p. $153-154^{\circ} / 11 \mathrm{~mm}, n_{\mathrm{D}^{20}} 1.4343, d_{4}{ }^{20} 1.0471$, $r_{\mathrm{D}} 0.2489$. Möller ${ }^{20}$ reported b. p. $156-158^{\circ} / 15 \mathrm{~mm}$ for the same compound prepared from diethyl methylmalonate and ethyl a-bromoisobutyrate, and Ruhl 10 reported b.p. $142-145^{\circ} / 5 \mathrm{~mm}$ for a sample prepared from diethyl methylmalonate and ethyl metha. crylate.

The reaction was also carried out with methylene iodide instead of the bromide. Diethyl carbonate was obtained in $61 \%$ yield and the triester in $87 \%$ yield.

$a, a^{\prime}$-Dimethylglutaric acid. The 1,3-dimethyl-1,1,3-tricarbethoxypropane was hydrolyzed by boiling with $70 \%$ sulphuric acid until the oily layer had disappeared which required about $5 \mathrm{~h}$. The solution was cooled in ice and the solid was filtered and washed with a small amount of ice water. After drying in a vacuum desiccator the yield of the crude acid mixture was $92 \%$. The separation into diastereoisomers was made according to Möller ${ }^{20}$. A high-melting form was obtained, m. p. $140-141^{\circ}$, in $30 \%$ yield, and a low-melting, m. p. $125-127^{\circ}$, in $37 \%$ yield. Möller reported $139-140^{\circ}$ and $127^{\circ}$, respectively ${ }^{20}$.

Diethyl bromomethyl-methylmalonate. To a mixture of $23.0 \mathrm{~g}$ of $20 \%$ sodium-toluene dispersion and $100 \mathrm{ml}$ of dry toluene there was added 0.2 mole of diethyl methylmalonate at such a rate that the reaction mixture boiled gently. 0.4 mole of methylene bromide was added in one portion and the mixture was boiled with stirring for $3 \mathrm{~h}$. After cooling water was added, the toluene solution separated, washed with water, and dried with anhydrous magnesium sulphate. Distillation yielded $38.0 \mathrm{~g}$ of diethyl bromomethylmethylmalonate $\left(71 \%\right.$ ), b. p. $98-100^{\circ} / 3 \mathrm{~mm}, n_{\mathrm{D}^{20}} 1.4503, d_{4}^{20}$ 1.3085. (Found: C 40.7; $\mathrm{H}$ 5.8; $\mathrm{Br} 29.7 ; r_{\mathrm{D}} 0.2055$. Calc. for $\mathrm{C}_{9} \mathrm{H}_{15} \mathrm{O}_{4} \mathrm{Br}$ : $\left.\mathrm{C} 40.5 ; \mathrm{H} 5.7 ; \mathrm{Br} 29.9 ; r_{\mathrm{D}} 0.2051.\right)$

Reaction between diethyl bromomethylmethylmalonate and diethyl methylmalonate. 0.2 mole of sodium was dissolved in $70 \mathrm{ml}$ of absolute ethanol, 0.2 mole of diethyl methylmalonate added and finally 0.2 mole of diethyl bromomethyl-methylmalonate dropped into the warm solution during a period of $30 \mathrm{mir}$. The reaction mixture was boiled for $20 \mathrm{~h}$ and then worked up in the usual way. A $61 \%$ yield of diethyl carbonate and an $85 \%$ yield of II, $\mathrm{R}=\mathrm{CH}_{3}$, were obtained.

1,3-Diethyl-1,1,3-tricarbethoxypropane $\left(I I, R=C_{2} H_{5}\right)$. This compound was prepared as the methyl derivative from 0.2 mole of sodium in $80 \mathrm{ml}$ of absolute ethanol, 0.2 mole of diethyl ethylmalonate, and 0.1 mole of methylene bromide. The reaction yielded $7.2 \mathrm{~g}$ $(61 \%)$ of diethyl carbonate and $20.8 \mathrm{~g}(66 \%)$ of 1,3-diethyl-1,1,3-tricarbethoxypropane, b.p. $144-145^{\circ} / 4 \mathrm{~mm}, n_{\mathrm{D}^{20}} 1.4395, d_{4}^{20} 1.0321$. (Found: $\mathrm{C} 60.4 ; \mathrm{H} 9.1 ; r_{\mathrm{D}} 0.255 \mathrm{l}$. Calc. for $\mathrm{C}_{16} \mathrm{H}_{28} \mathrm{O}_{6}$ : C $60.7 ; \mathrm{H} 8.9 ; r_{\mathrm{D}} 0.2566$.)

When methylene iodide was used in the above reaction, a $46 \%$ yield of diethyl carbonate and a $56 \%$ yield of triester were obtained.

$a, a^{\prime}$-Diethylglutaric acid. 1,3-Diethyl-1,1,3-tricarbethoxypropane was hydrolyzed by boiling over night with $75 \%$ sulphuric acid. The yield of crude acid mixture was $90 \%$, and it was separated into diastereoisomers according to the method of Berner and Land. mark ${ }^{21}$. The high-melting acid was obtained in $32 \%$ yield, m. p. $118-121^{\circ}$, and the lowmelting one in $25 \%$ yield, m. p. $92-94^{\circ}$. Berner and Landmark reported $119-120^{\circ}$ and 93.5-94.5

Diethyl bromomethyl-ethylmalonate. This synthesis was carried out in exactly the same way as for diethyl bromomethyl-methylmalonate from $23.0 \mathrm{~g}$ of $20 \%$ sodium-toluene dispersion in $100 \mathrm{ml}$ of dry toluene, 0.2 mole of diethyl ethylmalonate and 0.4 mole of methylene bromide. $27.0 \mathrm{~g}(48 \%)$ of the bromo compound was obtained, b.p. $105-107^{\circ} / 3$ $\mathrm{mm}, n_{\mathrm{D}}{ }^{20} 1.4521, d_{4}{ }^{20} 1.2753$. (Found: $\mathrm{C} \mathrm{43.0;} \mathrm{H} 6.1 ; \mathrm{Br} 28.6 ; r_{\mathrm{D}} 0.2117$. Calc. for $\left.\mathrm{C}_{10} \mathrm{H}_{17} \mathrm{O}_{4} \mathrm{Br}: \mathrm{C} 42.7 ; \mathrm{H} 6.1 ; \mathrm{Br} 28.4 ; r_{\mathrm{D}} 0.2114.\right)$

Kötz and Zörnig ${ }^{22}$ have prepared the corresponding chloromethyl and iodomethyl derivatives.

1,3-Di-n-propyl-1,1,3-tricarbethoxypropane $\left(I I, R=\mathrm{n}-\mathrm{C}_{\mathrm{3}} H_{7}\right)$. From 0.2 mole of sodium dissolved in $80 \mathrm{ml}$ of absolute ethanol, 0.2 mole of diethyl $n$-propylmalonate, and 0.1 mole of methylene bromide were obtained $6.0 \mathrm{~g}(51 \%)$ of diethyl carbonate and $23.4 \mathrm{~g}$ $(68 \%)$ of the triester, b.p. $152-153^{\circ} / 2 \mathrm{~mm}, n_{D^{20}} 1.4415, d_{4}^{20} 1.0091$. (Found: C 62.7; $\mathrm{H} 9.2 ; r_{D} 0.2619$. Calc. for $\mathrm{C}_{18} \mathrm{H}_{32} \mathrm{O}_{6}$ : C 62.8; $\mathrm{H} 9.4 ; r_{D} 0.2611$.) 
$\alpha, \alpha^{\prime}-D i$-n-propylglutaric acid. The triester was hydrolyzed by boiling over night with $10 \%$ ethanolic potassium hydroxide. The ethanol was distilled off and the triacid precipitated in almost quantitative yield upon acidification with concentrated hydrochloric acid. A small amount was recrystallized from ethyl acetate-petroleum ether, m. p. 165$170^{\circ}$ (decomp.) (Found: C 55.1; H 7.8. Calc. for $\mathrm{C}_{12} \mathrm{H}_{20} \mathrm{O}_{6}$ : C 55.4; $\mathrm{H}$ 7.8.)

The crude triacid was decarboxylated by heating to about $170^{\circ}$ until the gas evolution ceased. The resulting product was separated into two forms by fractionated crystallization from a mixture of ethyl acetate and petroleum ether (1:4) giving a $33 \%$ yield of the high-melting form, m. p. $110-112^{\circ}$, and a $19 \%$ yield of the low-melting form, m. p. $81-$ $82^{\circ}$. (Found for the high-melting form: $\mathrm{C} 61.1 ; \mathrm{H} \mathrm{9.3}$; equiv.wt. 107.8. Found for the low-melting form: C 61.0; $\mathrm{H}$ 9.3; equiv.wt. 108.6. Calc. for $\mathrm{C}_{11} \mathrm{H}_{20} \mathrm{O}_{4}$ : C 61.1; $\mathrm{H} \mathrm{9.3;}$ equiv.wt. 108.1.)

1,3-Diisopropyl-1,1,3-tricarbethoxypropane (II, $\left.R=\mathrm{i}-C_{3} H_{7}\right)$. This compound was prepared as before from 0.2 mole of sodium in $20 \mathrm{ml}$ of absolute ethanol and $100 \mathrm{ml}$ of dry toluene (the toluene was added in order to raise the boiling point), 0.2 mole of diethyl isopropylmalonate, and 0.1 mole of methylene bromide. $13.5 \mathrm{~g} \mathrm{(39 \% )} \mathrm{of} \mathrm{1,3-diisopropyl-}$ 1,1,3-tricarbethoxypropane was obtained, b.p. $153-155^{\circ} / 4 \mathrm{~mm}, n_{\mathrm{D}^{20}} 1.4462, d_{4}{ }^{20} 1.0219$. (Found: C 62.6; H 9.5; $r_{\mathrm{D}} 0.2627$. Calc. for $\mathrm{C}_{18} \mathrm{H}_{32} \mathrm{O}_{6}: \mathrm{C} 62.8 ; \mathrm{H} 9.4 ; r_{\mathrm{D}} 0.2611$.) No attempt to isolate the diethyl carbonate formed was made as its boiling point differs too little from that of toluene.

$a, \alpha^{\prime}$-Diisopropylglutaric acid. The triester was hydrolyzed by boiling with $80 \%$ sulphuric acid for $6 \mathrm{~h}$. The yield of crude acid mixture was $94 \%$. The mixture was dissolved in benzene, treated with decolorizing carbon and allowed to cool. Crystals rich in the high-melting modification separated and were filtered off. From the mother liquor crystals rich in the low-melting form could be isolated. The final purification was performed by two crystallizations from hot water, the melting points of the pure acids being $140-141^{\circ}$ and $118-119^{\circ}$, respectively. The yields were 40 and $23 \%$, respectively. (Found for the high-melting form: $\mathrm{C} \mathrm{60.7;} \mathrm{H}$ 9.3; equiv.wt. 108.3. Found for the lowmelting form: C 60.8; $\mathrm{H}$ 9.3; equiv.wt. 107.8. Calc. for $\mathrm{C}_{11} \mathrm{H}_{20} \mathrm{O}_{4}$ : C 61.1; $\mathrm{H}$ 9.3; equiv.wt. 108.1.)

1,3-Di-n-butyl-1,1,3-tricarbethoxypropane (II, $\left.R=\mathrm{n}-C_{4} H_{9}\right)$. From 0.2 mole of sodium dissolved in $80 \mathrm{ml}$ of absolute ethanol, 0.2 mole of diethyl $n$-butylmalonate, and 0.1 mole of methylene bromide were obtained $6.2 \mathrm{~g} \mathrm{(53 \% )}$ of diethyl carbonate and $27.5 \mathrm{~g}$ $(74 \%)$ of the triester, b.p. $180-182^{\circ} / 7 \mathrm{~mm}, n_{\mathrm{D}^{20}} 1.4433, d_{4}{ }^{20} 0.9936$. (Found: $\mathrm{C} \mathrm{64.3}$; $\mathrm{H}$ 9.6; $r \mathrm{D} 0.2670$. Calc. for $\mathrm{C}_{20} \mathrm{H}_{36} \mathrm{O}_{6}:$ C 64.5; $\mathrm{H} 9.7 ; r_{\mathrm{D}}$ 0.2679.)

$\alpha, \alpha^{\prime}-D i$-n-butylglutaric acid. The triester was hydrolyzed by boiling over night with $10 \%$ ethanolic potassium hydroxide. The ethanol was distilled off and the triacid precipitated in quantitative yield upon acidification with concentrated hydrochloric acid. A small amount was recrystallized from ethyl acetate-petroleum ether, m. p. 155-160 (decomp.). (Found: C 58.3; $\mathrm{H}$ 8.5. Calc. for $\mathrm{C}_{14} \mathrm{H}_{24} \mathrm{O}_{6}$ : C 58.3; $\mathrm{H}$ 8.4.)

The crude triacid was decarboxylated by heating to about $170^{\circ}$ until the gas evolution ceased. The product solidified upon standing and the solid was dissolved in petroleum ether. After cooling in an ice-bath the crystals were filtered. They consisted of almost pure high-melting form. Two further fractions of crystals rich in the high-melting form were collected. They were combined and recrystallized once from petroleum ether, giving a $41 \%$ yield of the pure high-melting form, m. p. 92-93 . The mother liquor from the first filtration was evaporated and the residue left in a vacuum desiccator over night, whereby it solidified slowly. It could be recrystallized from petroleum ether if the solution was cooled to $-50^{\circ}$ and the crystals rapidly filtered, m. p. $53-56^{\circ}$, yield $21 \%$. Kögl and Erxleben ${ }^{23}$ have prepared the $\alpha, \alpha^{\prime}-d i-n$-butylglutaric acids by the reaction between disodium 1,1,3,3-tetracarbethoxypropane and $n$-butyl iodide followed by hydrolysis of the tetraester and decarboxylation. They found the m.p.'s $95-96^{\circ}$ and $53-56^{\circ}$, respectively.

1,3-Diisobutyl-1,1,3-tricarbethoxypropane (II, $\left.R=\mathrm{i}-\mathrm{C}_{4} H_{9}\right)$. From 0.2 mole of sodium dissolved in $80 \mathrm{ml}$ of absolute ethanol, 0.2 mole of diethyl isobutylmalonate, and 0.1 mole of methylene bromide were obtained $4.2 \mathrm{~g}(34 \%)$ of diethyl carbonate and $19.0 \mathrm{~g}$ $(51 \%)$ of the triester, b.p. $152-4^{\circ} / 1.5 \mathrm{~mm}, n_{\mathrm{D}}{ }^{20}$ 1.4428, $d_{4}{ }^{20} 0.9929$. (Found: $\mathrm{C} \mathrm{64.3}$; $\mathrm{H} 10.0 ; r_{D} 0.2669$. Calc. for $\mathrm{C}_{20} \mathrm{H}_{36} \mathrm{O}_{6}: \mathrm{C} 64.5 ; \mathrm{H} \mathrm{9.7;} r_{\mathrm{D}} 0.2679$.)

$a, a^{\prime}$-Diisobutylglutaric acid. The triester was hydrolyzed by boiling over night with $10 \%$ ethanolic potassium hydroxide. The ethanol was distilled off and the triacid preci- 
pitated with concentrated hydrochloric acid in quantitative yield. A small amount was recrystallized from ethyl acetate-petroleum ether, m. p. $165-170^{\circ}$ (decomp.). (Found: C 58.3; $\mathrm{H}$ 8.4. Calc. for $\mathrm{C}_{14} \mathrm{H}_{24} \mathrm{O}_{6}$ : C 58.3; $\mathrm{H}$ 8.4.)

The crude triacid was decarboxylated by heating to about $170^{\circ}$ until the gas evolution ceased. The product solidified upon cooling and could be separated into two forms by fractionated crystallization from petroleum ether as in the case of the $n$-butyl derivative. A $28 \%$ yield of the high-melting form, m. p. 85-87 , and a $23 \%$ yield of the lowmelting one, m. p. $80-82^{\circ}$ were obtained. The high-melting isomer was found to be monotropic and transformed to a stable crystalline modification at about $90^{\circ}$, which then melted at $101-102^{\circ}$. When the liquid was allowed to solidify above $90^{\circ}$ the stable form crystallized, whereas solidification at temperatures below this point gave the unstable form with the m. p. 85-87 . (Found for the high-melting form: C 63.8; H 9.9; equiv.wt. 121.6. Found for the low-melting form: $\mathrm{C} 63.9 ; \mathrm{H} 10.1$; equiv.wt. 121.4. Calc. for $\mathrm{C}_{13} \mathrm{H}_{24} \mathrm{O}_{4}$ : C $63.9 ; \mathrm{H}$ 9.9; equiv.wt. 122.1.)

1,3-Di-n-amyl-1,1,3-tricarbethoxypropane (II, $\left.R=\mathrm{n}-C_{5} H_{11}\right)$. From 0.2 mole of sodium dissolved in $80 \mathrm{ml}$ of absolute ethanol, 0.2 mole of diethyl $n$-amylmalonate, and 0.1 mole of methylene bromide were obtained $6.7 \mathrm{~g}(57 \%)$ of diethyl carbonate and $31.0 \mathrm{~g}$ $\left(77 \%\right.$ ) of the triester, b.p. $168-171^{\circ} / 2 \mathrm{~mm}, n_{\mathrm{D}^{20}} 1.4443, d_{4}{ }^{20} 0.9797$. (Found: $\mathrm{C} \mathrm{65.7;}$ $\mathrm{H} 10.0 ; r_{\mathrm{D}} 0.2713$. Calc. for $\mathrm{C}_{22} \mathrm{H}_{40} \mathrm{O}_{8}: \mathrm{C} 65.9 ; \mathrm{H} 10.1 ; r_{\mathrm{D}} 0.2724$.)

$a, \alpha^{\prime}-D i$-n-amylglutaric acid. The triester was boiled over night with $10 \%$ ethanolic potassium hydroxide. The ethanol was distilled off, and the triacid precipitated in quantitative yield with hydrochloric acid. A small amount was recrystallized from ethyl acetate-petroleum ether, m. p. $140-142^{\circ}$. (Found: C 60.5; H 8.9. Calc. for $\mathrm{C}_{16} \mathrm{H}_{28} \mathrm{O}_{6}: \mathrm{C} 60.7$; H 8.9.)

The crude acid was decarboxylated by heating to $170^{\circ}$ until the gas evolution ceased, and the acid mixture was dissolved in petroleum ether, filtered, and allowed to cool. The crystals were filtered, and the mother liquor was evaporated to half its volume. A further fraction of crystals was obtained which was combined with the first one and recrystallized from petroleum ether, m. p. $113-5^{\circ}$. After evaporation of the mother liquor from the second filtration an oil was obtained, which turned to a semisolid mass upon standing. Attempts to isolate the other form from this were not successful, owing to its very poor crystallizing properties and great solubility in the common solvents. The yield of the isomer with m.p. $113-115^{\circ}$ was $43 \%$. (Found for the isomer with m. p. $113-115^{\circ}$ : $\mathrm{C}$ 66.1; $\mathrm{H}$ 10.3; equiv.wt. 136.7. Calc. for $\mathrm{C}_{15} \mathrm{H}_{28} \mathrm{O}_{4}$ : $\mathrm{C} 66.1 ; \mathrm{H} 10.4$; equiv.wt. 136.2.)

Diethyl bromomethyl-n-amylmalonate. This compound was prepared as above from $23.0 \mathrm{~g}$ of $20 \%$ sodium dispersion in $100 \mathrm{ml}$ of dry toluene, 0.2 mole of diethyl $n$-amyl malonate, and 0.4 mole of methylene bromide. $34.0 \mathrm{~g} \mathrm{(53 \% )} \mathrm{of} \mathrm{the} \mathrm{bromo} \mathrm{compound} \mathrm{was}$ obtained, b. p. $132-133^{\circ} / 3 \mathrm{~mm}, n_{\mathrm{D}^{20}} 1.4534, d_{4}{ }^{20} 1.1831$. (Found: C $49.0 ; \mathrm{H} \mathrm{7.5} ; \mathrm{Br} 24.2$; $r_{D} 0.2286$. Calc. for $\mathrm{C}_{13} \mathrm{H}_{23} \mathrm{O}_{4} \mathrm{Br}$ : C $48.3 ; \mathrm{H} 7.2 ; \mathrm{Br} 24.7 ; r_{D} 0.2270$.)

Ethyl a-neopentylacrylate. When 0.2 mole of sodium dissolved in $80 \mathrm{ml}$ of absolute ethanol, 0.2 mole of diethyl neopentylmalonate * and 0.1 mole of methylene bromide was boiled for $24 \mathrm{~h}$ and the reaction mixture worked up in the usual manner the only isolable product except recovered starting material was $12.0 \mathrm{~g}(71 \%)$ of ethyl $\alpha$-neopentylacrylate, b.p. $68-70^{\circ} / 11 \mathrm{~mm}, n_{\mathrm{D}^{20}} 1.4273, d_{4}{ }^{20} 0.8806$. (Found: $\mathrm{C} 69.8 ; \mathrm{H} 10.7 ; r_{\mathrm{D}} 0.2917$. Calc. for $\mathrm{C}_{10} \mathrm{H}_{18} \mathrm{O}_{2}$ : C 70.5; $\mathrm{H} 10.7 ; r_{\mathrm{D}} 0.2915$.) The ester was hydrolyzed by boiling with $10 \%$ ethanolic potassium hydroxide. The ethanol was evaporated and the acid precipitated by hydrochloric acid. It soon solidified and was filtered and finally recrystallized from dilute acetic acid, m. p. $43-44^{\circ}$. The $p$-bromophenacyl ester had m. p. $53-55^{\circ}$. Hadley et al. ${ }^{8}$ reported for the acid m. p. $39^{\circ}$ and for its $p$-bromophenacyl ester $56^{\circ}$.

An attempt to carry out the reaction at $160^{\circ}$ in a steel bomb gave the same result.

Diethyl bromomethyl-neopentylmalonate. This compound was prepared as above from $23.0 \mathrm{~g}$ of $20 \%$ sodium-toluene dispersion in $100 \mathrm{ml}$ of dry toluene, 0.2 mole of diethyl neopentylmalonate, and 0.4 mole of methylene bromide. $24.0 \mathrm{~g}(37 \%)$ of the bromo compound was obtained, b.p. $147-150^{\circ} / 13 \mathrm{~mm}, n_{\mathrm{D}^{20}} 1.4588, d_{4}{ }^{20} 1.2035$. (Found: C 48.5; $\mathrm{H} 7.1 ; \mathrm{Br} 24.4 ; r_{\mathrm{D}} 0.2271$. Calc. for $\mathrm{C}_{13} \mathrm{H}_{23} \mathrm{O}_{4} \mathrm{Br}: \mathrm{C} 48.3 ; \mathrm{H} \mathrm{7.2;} \mathrm{Br} 24.7 ; r_{\mathrm{D}} 0.2270$. )

\footnotetext{
* The author is indebted to docent A. Brändström, AB Pharmacia, Uppsala, for this material.
}

Acta Chem. Scand. 12 (1958) No. 2 
Diethyl a, $\alpha^{\prime}$-diphenylglutarate $\left(I V, R^{\prime}=C_{6} H_{5}\right)$. This compound was prepared as above from 0.2 mole of sodium dissolved in $80 \mathrm{ml}$ of absolute ethanol, $0.2 \mathrm{~mole}$ of diethyl phenylmalonate, and 0.1 mole of methylene bromide. $19.0 \mathrm{~g}(80 \%)$ of diethyl carbonate and $21.5 \mathrm{~g}(63 \%)$ of very viscous diethyl $a \alpha^{\prime}$-diphenylglutarate, b. p. $183-184^{\circ} / 1 \mathrm{~mm}$, $n_{\mathrm{D}^{20}} 1.5274$, was obtained. Souther ${ }^{7}$ reported b.p. $216-217^{\circ} / 7 \mathrm{~mm}$.

$a, a^{\prime}$-Diphenylglutaric acid. The diethyl ester was hydrolyzed by boiling with $10 \%$ ethanolic potassium hydroxide for one hour, and the acid mixture obtained was separated into diastereoisomers by fractionated crystallization from benzene. The melting points and yields of the pure acids were $187-188^{\circ}(40 \%)$ and $159-160^{\circ}(22 \%)$, respectively. Souther $^{7}$ reported the melting points $185-186.5^{\circ}$ and $164.5-165.5^{\circ}$.

1,3-Dibenzyl-1,1,3-tricarbethoxypropane $\left(I I, R=\mathrm{C}_{6} \mathrm{H}_{5} \mathrm{CH}_{2}\right)$. From 0.2 mole of sodium in $80 \mathrm{ml}$ of ethanol, 0.2 mole of diethyl benzylmalonate, and 0.1 mole of methylene bromide were obtained $5.8 \mathrm{~g}(49 \%)$ of diethyl carbonate and $34.0 \mathrm{~g}(77 \%)$ of the very viscous triester, b.p. $224-227^{\circ} / 2 \mathrm{~mm}, n_{\mathrm{D}}{ }^{20}$ 1.5176. (Found: C 70.7; H 7.4. Calc. for $\mathrm{C}_{28} \mathrm{H}_{28} \mathrm{O}_{8}:$ C $\left.70.9 ; \mathrm{H} 7.3.\right)$

The reaction was also carried out with methylene iodide whereby a $72 \%$ yield of the triester was obtained.

$a, \alpha^{\prime}$-Dibenzylglutaric acid. The triester was hydrolyzed by boiling over night with $10 \%$ ethanolic potassium hydroxide. The ethanol was distilled off and the acid precipitated by hydrochloric acid in quantitative yield. A small amount was recrystallized from ethyl acetate-petroleum ether, m. p. $155-160^{\circ}$ (decomp.). (Found: C 67.4; H 5.7. Calc. for $\mathrm{C}_{20} \mathrm{H}_{20} \mathrm{O}_{8}$ : C 67.3; $\mathrm{H}$ 5.7.)

The crude acid was decarboxylated by heating to $170^{\circ}$ until the gas evolution ceased, and the acid mixture was dissolved in benzene, filtered, and allowed to cool. The crystals were filtered off and from the mother liquor one further fraction with about the same melting point was obtained. The combined fractions were recrystallized two times from $80 \%$ acetic acid, m. p. $149-150^{\circ}$. The mother liquor from the second filtration was evaporated. The residue was a crystal mass with m. p. $120-140^{\circ}$. In spite of many recrystallizations from various solvents and solvent pairs no sharply melting isomer could be obtained from this. (Found for the isomer with $\mathrm{m}$. p. 149-150 : C 72.8; H 6.5; equiv.wt. 155.3. Found for the crystals with m. p. $120-140^{\circ}:$ C 72.9; H 6.5; equiv.wt. 156.0. Calc. for $\mathrm{C}_{19} \mathrm{H}_{20} \mathrm{O}_{4}$ : C 73.1; $\mathrm{H} \mathrm{6.5;} \mathrm{equiv.wt.} \mathrm{156.2.)}$

Reaction between tricarbethoxymethane and methylene bromide. From 0.2 mole of sodium dissolved in $80 \mathrm{ml}$ of absolute ethanol, 0.2 mole of tricarbethoxymethane, and 0.1 mole of methylene bromide $12.2 \mathrm{~g}(52 \%)$ of diethyl carbonate and $18.3 \mathrm{~g} \mathrm{(55 \% )} \mathrm{of} \mathrm{1,1,3,3-tetra-}$ carbethoxypropane, b.p. $189-191^{\circ} / 11 \mathrm{~mm}$ were obtained.

$a, \alpha^{\prime}$-Diaminoglutaric acid. 0.2 mole of sodium was dissolved in $150 \mathrm{ml}$ of absolute ethanol, 0.2 mole of diethyl acetaminomalonate was added followed by 0.1 mole of methylene bromide. The reaction mixture was boiled for $36 \mathrm{~h}$, filtered and the ethanol distilled off on the water-bath through a short column. Then the pressure was lowered to about $60 \mathrm{~mm} \mathrm{Hg}$ and a small amount, $2.1 \mathrm{~g}(18 \%)$, of diethyl carbonate was collected. The residue, which was contaminated with unreacted starting material and sodium bromide, was hydrolyzed directly according to the method of Hellman et al. The yield of pure $\alpha, \alpha^{\prime}$-diaminoglutaric acid was $3.6 \mathrm{~g}(23 \%)$. It darkens and decomposes at $270-280^{\circ}$.

The author wishes to express his sincere gratitude to Professor Erik Larsson for his kind interest in this work. A grant from the Kungliga Fysiografiska Sällskapet is gratefully acknowledged.

\section{REFERENCES}

1. Eberson, L. Acta Chem. Scand. 9 (1955) 1711.

2. Guthzeit, M. and Dressel, O. Ber. 21 (1888) 2233.

3. Guthzeit, M. and Dressel, O. Ann. 256 (1890) 171.

4. Bischoff, C. A. Ber. 23 (1890) 1464.

5. Auwers, K. and Thorpe, J. F. Ann. 285 (1895) 310.

6. Hellman, H., Lingens, F. and Folz, E. Chem. Ber. 89 (1956) 2433.

7. Souther, B. L. J. Am. Chem. Soc. 46 (1924) 1301.

8. Hadley, D. J., Hall, R. H., Heap, R. and Jacobs, D. I. H. J. Chem. Soc. 19541416.

9. Wislicenus, W. and Goldstein, K. Ber. 28 (1895) 815. 
10. Cope, A. C. and McElvain, S. M. J. Am. Chem. Soc. 54 (1932) 4319.

11. Connor, R. J. Am. Chem. Soc. 55 (1933) 4597.

12. Boyd, R. N. and Kelly, R. J. J. Am. Chem. Soc. 74 (1952) 4600.

13. Cope, A. C. and McElvain, S. M. J. Am. Chem. Soc. 54 (1932) 4311.

14. v. Richter, V. Ber. 21 (1888) 2470.

15. Ingold, C. K. and Thorpe, J. F. J. Chem. Soc. 115 (1919) 143.

16. Bowman, N. S. and Rexford, D. R. J. Org. Chem. 19 (1954) 1219.

17. Auwers, K. and Köbner, E. Ber. 24 (1891) 1923.

18. Hoch, D. and Karrer, P. Helv. Chim. Acta 37 (1954) 397.

19. Ruhl, K. Z. Naturforsch. 4 b (1949) 199.

20. Möller, E. Kgl. Fysiograf. Sällskap. Lund, Förh. 30 (1918) Nr 6.

21. Berner, E. and Landmark, L. H. Acta Chem. Scand. 7 (1953) 1347.

22. Kötz, A. and Zörnig, W. J. prakt. Chem. 74 (1906) 425.

23. Kögl, F., Erxleben, H., Michaelis, R. and Visser, H. S. Hoppe-Seyler's Z. physiol. Chem. 235 (1935) 181.

Received November 8, 1957. 